\title{
INFLUENCIA DE INIBIDORES NO PROCESSO DE FERMENTAÇÃO ETANÓLICA DE XILOSE POR PACHYSOLEN TANNOPHILUS
}

\author{
A. S. SILVA ${ }^{1}$, A. M. OLIVEIRA Jr ${ }^{1}$ e A. K. S. ABUD ${ }^{1}$ \\ ${ }^{1}$ Universidade Federal de Sergipe, Departamento de Tecnologia de Alimentos \\ E-mail para contato: ana.abud@gmail.com
}

\begin{abstract}
RESUMO - Nos processos de produção de etanol de segunda geração fazem-se necessárias etapas de pré-tratamento para a quebra da lignina e da hemicelulose, redução da cristalinidade da celulose e aumento da porosidade da biomassa. Estes pré-tratamentos liberam não apenas hexoses, mas também pentoses e outros açúcares, além de inibidores. Avalia-se neste trabalho o efeito dos inibidores ácido acético, furfural $\mathrm{e}$ hidroximetilfurfural na cinética de produção de etanol pela levedura Pachysolen tannophilus, à temperatura ambiente, durante $120 \mathrm{~h}$, tendo como substrato a xilose comercial. A adição de hidroximetilfurfural não influenciou o processo fermentativo e, apesar de geração de biomassa inferior ao processo sem adição de inibidores, foi a que obteve maior eficiência na conversão de xilose a etanol (22,9\%). Os resultados mostraram que a levedura Pachysolen tannophilus é inibida pela presença de ácido acético e furfural, indicando que a levedura pode não ser eficiente em amostras de pré-tratamento da biomassa lignocelulósica que contenham uma mistura destes inibidores.
\end{abstract}

\section{INTRODUÇÃO}

A demanda brasileira e mundial por combustíveis renováveis tem aumentado consideravelmente nos últimos anos, tanto por questões econômicas (alto preço dos combustíveis fósseis) quanto por socioambientais, reduzindo a emissão de gases de efeito estufa que contribuem para o aquecimento global (Demirbas, 2005 citado por Cabral et al., 2009).

Para suprir esta demanda, buscam-se processos industriais economicamente viáveis e sustentáveis, sendo um dos focos de intensa pesquisa e desenvolvimento os processos de produção de bioetanol a partir de biomassas alternativas, a exemplo do material lignocelulósico, que somente no Brasil totaliza 350 milhões de toneladas por ano e englobam resíduos agroindustriais, lixo urbano, resíduos florestais, entre outros, participando em aproximadamente $50 \%$ da biomassa terrestre (Ballesteros, 2001; Pereira Jr, 2007; Hayes, 2009).

A biomassa lignocelulósica é constituída de celulose, hemicelulose e lignina que, quando hidrolisados, disponibilizam uma fração de hexoses resultante da celulose, facilmente fermentescível, e uma fração de pentoses, resultante das hemiceluloses, que são carboidratos não diretamente fermentescíveis pelas leveduras industriais, tradicionalmente utilizadas na conversão de bioetanol 


\section{9 a 22 de outubro de 2014 \\ Florianópolis/SC}

(Machado, 2013). As hemiceluloses são heteropolímeros de pentoses e hexoses e a hidrólise das hemiceluloses fornece, principalmente, pentoses, onde a xilose é o açúcar predominante, compreendendo 20 a 40\% do total de carboidratos dos resíduos agrícolas (Gírio et al., 2010; Moraes et al., 2010). Para a utilização eficaz da biomassa lignocelulósica, não se deve levar em conta apenas a fermentação de hexoses, mas, também, a de pentoses, atualmente considerado um dos desafios mais importantes a ser resolvido no âmbito científico e tecnológico (Gírio et al., 2010; Rossell, 2008; Silva et al., 2011).

Diferentes espécies de leveduras e microrganismos geneticamente modificados têm sido analisadas para a produção de etanol, com rendimento suficiente para tornar o processo economicamente atrativo (Fugita, 2010; Almeida, 2011), destacando-se as leveduras Pichia stipitis, Candida shehatae e Pachysolen tannophilus e as bactérias Zymomonas mobilis e Escherichia coli, cada uma apresentando seus aspectos positivos e negativos na produção de bioetanol (Gírio et al., 2010; Machado, 2013).

De acordo com Zhao et al. (2008), a levedura Pachysolen tannophilus é um dos maiores produtores de etanol a partir de xilose, apesar de não tolerar altas concentrações deste produto. A fermentação contendo mistura de glicose e xilose mostra a preferência da levedura pela hexose, enquanto que na fermentação apenas com xilose observa-se maior formação de biomassa e menor produção de etanol.

Em estratos do pré-tratamento da biomassa lignocelulósica, a fermentação costuma ser lenta e de baixo rendimento, o que provavelmente deve estar relacionado à baixa resistência dos microrganismos a altas concentrações de etanol, além de haver a geração de vários co-produtos, tais como ácido acético e ácido lático, considerados produtos de degradação. Além destes, o ácido fórmico, o furfural, o hidroximetilfurfural e fenóis podem, também, ser produzidos durante o processo, inibindo a fermentação e afetando o rendimento de produção do etanol, devendo, assim, serem removidos ou suavizados (Fugita, 2010).

Este trabalho analisa a influência dos principais inibidores formados no pré-tratamento da biomassa lignocelulósica, ácido acético, furfural e hidroximetilfurfural, no processo de fermentação etanólica em meio sintético, com a levedura Pachysolen tannophilus, contendo xilose única fonte de carboidrato.

\section{METODOLOGIA}

\subsection{Microrganismo e inóculo}

Utilizou-se nos experimentos a levedura Pachysolen tannophilus NRRL Y-2460, gentilmente cedida pela Embrapa Agroenergia. A manutenção da linhagem foi realizada a partir de repiques contínuos em meio YPX (20 g/L de extrato de levedura; $10 \mathrm{~g} / \mathrm{L}$ de peptona e $20 \mathrm{~g} / \mathrm{L}$ de xilose), sendo a cultura mantida em tubo inclinado contendo meio YPXA (20 g/L de extrato de levedura; $10 \mathrm{~g} / \mathrm{L}$ de peptona; $20 \mathrm{~g} / \mathrm{L}$ de xilose e $20 \mathrm{~g} / \mathrm{L}$ de ágar bacteriológico). 


\section{9 a 22 de outubro de 2014 \\ Florianópolis/SC}

O meio de cultura sintético foi composto por $20 \mathrm{~g} / \mathrm{L}$ xilose, $3 \mathrm{~g} / \mathrm{L}$ extrato de levedura, $5 \mathrm{~g} / \mathrm{L}$ peptona bacteriológica, $1 \mathrm{~g} / \mathrm{L}$ sulfato de magnésio $\left(\mathrm{MgSO}_{4}\right), 5 \mathrm{~g} / \mathrm{L}$ fosfato de potássio monobásico $\left(\mathrm{KH}_{2} \mathrm{PO}_{4}\right)$ e $3 \mathrm{~g} / \mathrm{L}$ sulfato de amônio $\left[\left(\mathrm{NH}_{4}\right)_{2} \mathrm{SO}_{4}\right]$. $\mathrm{O} \mathrm{pH}$ do foi corrigido para 4,5 e, em seguida, esterilizado em autoclave à $121^{\circ}$ e $1 \mathrm{~atm}$ por $15 \mathrm{~min}$, sendo a xilose esterilizada em separado.

Para o preparo do inóculo, alçadas da levedura foram transferidas assepticamente para frasco Erlenmeyer de $500 \mathrm{~mL}$ contendo $250 \mathrm{~mL}$ de meio de cultura e incubado à temperatura ambiente e sob agitação de $150 \mathrm{rpm}$ por $24 \mathrm{~h}$ (fase exponencial de crescimento). Depois deste tempo, foi realizada a contagem de células em câmara de Neubauer para determinar o volume necessário para inocular $2.10^{7}$ cél $/ \mathrm{mL}$. Com o volume definido, as células foram recuperadas por centrifugação a $3750 \mathrm{rpm}$ e $10 \mathrm{~min}$, sendo posteriormente ressuspensas no meio de fermentação.

\subsection{Processo fermentativo}

Para os testes fermentativos foi utilizado o meio contendo $20 \mathrm{~g} / \mathrm{L}$ xilose; $3 \mathrm{~g} / \mathrm{L}$ extrato de levedura; $5 \mathrm{~g} / \mathrm{L}$ peptona bacteriológica; $1 \mathrm{~g} / \mathrm{L}$ sulfato de magnésio $\left(\mathrm{MgSO}_{4}\right) ; 5 \mathrm{~g} / \mathrm{L}$ fosfato de potássio monobásico $\left(\mathrm{KH}_{2} \mathrm{PO}_{4}\right) ; 3 \mathrm{~g} / \mathrm{L}$ sulfato de amônio $\left[\left(\mathrm{NH}_{4}\right)_{2} \mathrm{SO}_{4}\right]$. Para o teste de inibição foram adicionadas quantidades determinadas dos inibidores ácido acético $(1,75 \mathrm{~g} / \mathrm{L})$, furfural $(1,25 \mathrm{~g} / \mathrm{L}) \mathrm{e}$ hidroximetil furfural $(0,40 \mathrm{~g} / \mathrm{L})$. $\mathrm{O} \mathrm{pH}$ do meio foi ajustado para 4,5, com solução de ácido sulfúrico 1,5 M ou hidróxido de sódio $2 \mathrm{M}$. Os experimentos foram conduzidos frascos Erlenmeyer de $250 \mathrm{~mL}$, à temperatura ambiente por $120 \mathrm{~h}$, sem controle de $\mathrm{pH}$. Durante os experimentos, amostras foram retiradas a cada $24 \mathrm{~h}$ para determinação do crescimento celular, consumo de xilose e produção de etanol. As fermentações foram realizadas em duplicata.

\subsection{Determinações analíticas}

O acompanhamento do crescimento celular foi feito através da medida de absorbância a 600 $\mathrm{nm}$, tendo água destilada como branco. Os valores de concentração foram calculados através de equação de curva de calibração entre o peso e a absorbância. A concentração de xilose foi determinada pelo método colorimétrico do ácido 3,5-dinitrossalicílico (DNS), após fervura por $5 \mathrm{~min}$ e leitura em espectrofotômetro a $540 \mathrm{~nm}$, de acordo com metodologia proposta por Miller (1959), tendo como curva padrão soluções de concentração conhecida de xilose. A concentração de etanol foi determinada por cromatografia gasosa, em detector de ionização de chama (FID), com coluna Restek RT-Q-Bond, isoterma a $150^{\circ} \mathrm{C}$, injeção split $60 \mathrm{~mL} / \mathrm{min}$, temperatura do injetor e do detetor a $250^{\circ} \mathrm{C} \mathrm{e}$ tempo de análise de 3 min. As medidas foram realizadas em triplicata.

Para avaliar a influência da inibição da levedura em estudo pela presença dos inibidores, foram calculados o rendimento em etanol ( $\left.\mathrm{Y}_{\mathrm{P} / \mathrm{S}}, \mathrm{g} / \mathrm{g}\right)$, definido pela razão entre a concentração de etanol $(\mathrm{g} / \mathrm{L})$ e a xilose consumida $(\mathrm{g} / \mathrm{L})$, a conversão de substrato em células $\left(\mathrm{Y}_{\mathrm{X} / \mathrm{S}}, \mathrm{g} / \mathrm{g}\right)$, como a razão entre a variação do crescimento celular e a xilose consumida, a produtividade em etanol $\left(Q_{P}, g / L . h\right)$, pela razão entre a variação máxima da concentração de etanol $(\mathrm{g} / \mathrm{L})$ e o tempo desta fermentação 


\section{RESULTADOS E DISCUSSÃO}

Para entender o comportamento da levedura frente à presença dos principais inibidores do prétratamento da biomassa lignocelulósica, do qual se extrai a hemicelulose, foram realizados estudos de fermentação em xilose comercial na ausência, na mistura e na presença de cada inibidor, cuja concentração foi definida com base em experimentos conduzidos por García-Cubero et al. (2011) com a levedura Pichia stipitis.

Os perfis das cinéticas de fermentação são apresentados na Figura 1. Pode-se observar que a Pachysolen tannophilus se mostrou capaz de crescer na presença apenas do hidroximetilfurfural (HMF), gerando produção máxima de etanol. A adição de ácido acético (HAc) inibiu o processo fermentativo, não chegando a consumir metade da xilose adicionada. A adição de furfural (F) inibiu o crescimento nas primeiras $96 \mathrm{~h}$ de fermentação, ainda que praticamente toda a xilose fosse consumida. O processo sem adição de inibidores apresentou maior formação de biomassa, porém produção de etanol inferior ao processo com adição de HMF.
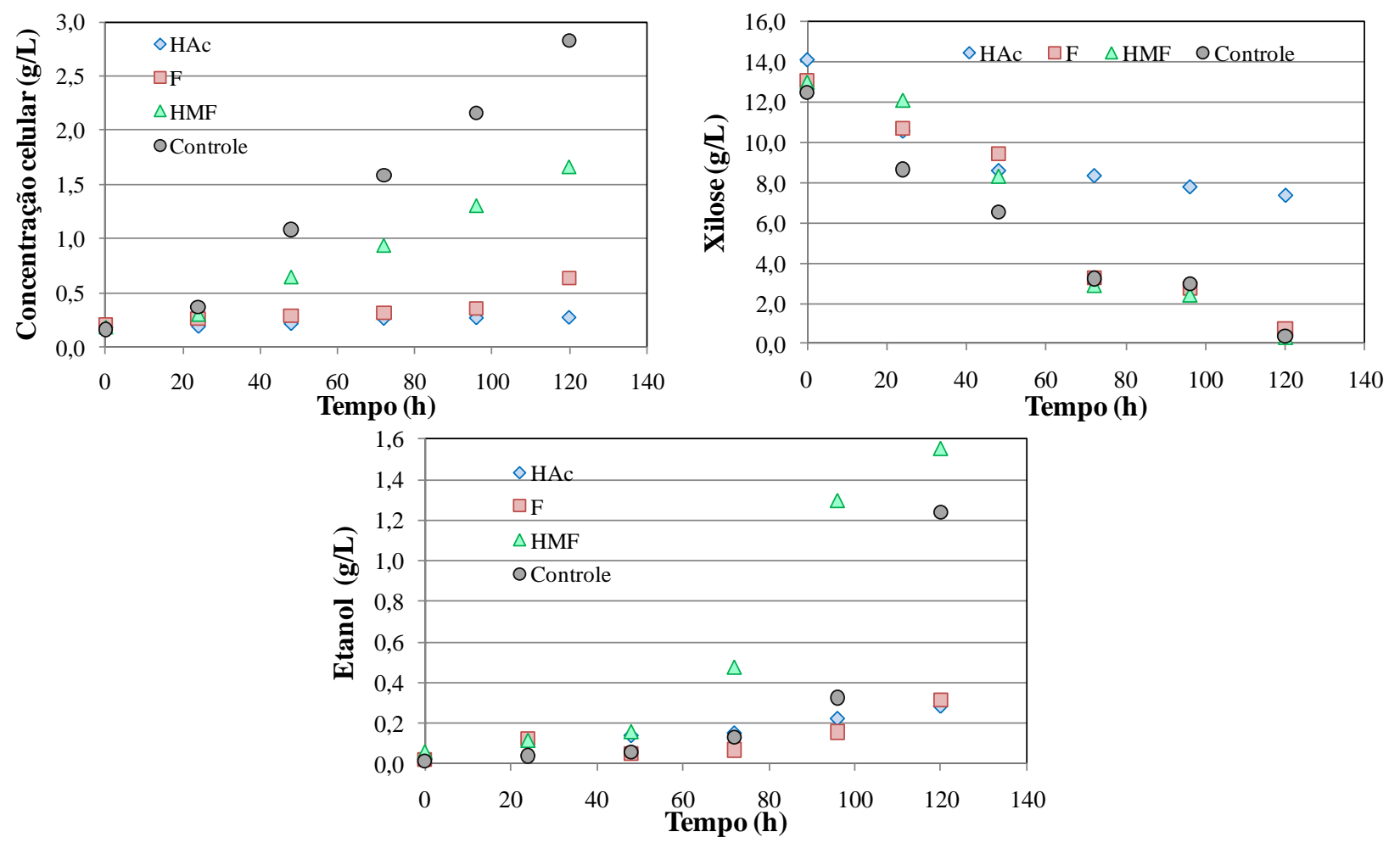

Figura 1 - Comportamento cinético das variáveis de fermentação.

A Tabela 1 apresenta as variações de crescimento celular $(\Delta \mathrm{X})$, consumo de substrato $(\Delta \mathrm{S})$ e produção de etanol $(\Delta \mathrm{P})$ após $120 \mathrm{~h}$ de fermentação, bem como os valores encontrados para os parâmetros $\mathrm{Y}_{\mathrm{P} / \mathrm{S}}, \mathrm{Y}_{\mathrm{X} / \mathrm{S}}, \mu_{\max }, \mathrm{Q}_{\mathrm{P}}$ e eficiência da conversão de xilose à etanol $(\eta \%)$, utilizando-se 0,511 
g/g como valor teórico da conversão de açúcar em etanol.

Tabela 1 - Parâmetros cinéticos e de conversão obtidos nos ensaios realizados.

\begin{tabular}{cccccccccc}
\hline & $\begin{array}{c}\mathbf{\Delta X} \\
(\mathbf{g} / \mathbf{L})\end{array}$ & $\begin{array}{c}\mathbf{\Delta S} \\
(\mathbf{g} / \mathbf{L})\end{array}$ & $\begin{array}{c}\Delta \mathbf{P} \\
(\mathbf{g} / \mathbf{L})\end{array}$ & $\begin{array}{c}\mathbf{Y}_{\mathbf{X} / \mathbf{S}} \\
(\mathbf{g} / \mathbf{g})\end{array}$ & $\begin{array}{c}\mathbf{Y}_{\mathbf{P} / \mathbf{S}} \\
(\mathbf{g} / \mathbf{g})\end{array}$ & $\begin{array}{c}\boldsymbol{\mu}_{\max } \\
\left(\mathbf{h}^{-1}\right)\end{array}$ & $\begin{array}{c}\mathbf{Q}_{\mathbf{X}} \\
(\mathbf{g} / \mathbf{L} . \mathbf{h})\end{array}$ & $\begin{array}{c}\mathbf{Q}_{\mathbf{P}} \\
(\mathbf{g} / \mathbf{L} . \mathbf{h})\end{array}$ & $\begin{array}{c}\boldsymbol{\eta} \\
(\boldsymbol{\%})\end{array}$ \\
\hline Controle & 2,67 & 12,10 & 1,23 & 0,220 & 0,101 & 0,028 & 0,022 & 0,010 & 19,82 \\
HAc & 0,09 & 6,75 & 0,26 & 0,013 & 0,038 & 0,004 & 0,001 & 0,002 & 7,53 \\
F & 0,43 & 12,34 & 0,29 & 0,035 & 0,024 & 0,006 & 0,004 & 0,002 & 4,62 \\
HMF & 1,48 & 12,74 & 1,49 & 0,116 & 0,117 & 0,020 & 0,002 & 0,012 & 22,90 \\
\hline
\end{tabular}

A maior conversão de xilose em células ( $\left.\mathrm{Y}_{\mathrm{X} / \mathrm{S}}\right)$ ocorreu nos experimentos sem adição de inibidores $(0,22 \mathrm{~g} / \mathrm{g})$, tendo a adição de HMF um efeito 50\% inferior. Avaliando-se a produtividade de biomassa, o experimento controle $(0,022 \mathrm{~g} / \mathrm{L}$.h $)$ obteve resultados semelhantes ao encontrado por Sánchez et al. (2002) com $25 \mathrm{~g} / \mathrm{L}$ de xilose (0,023 g/L.h).

Nos ensaios sem adição de inibidores (controle) e com adição de HMF foram obtidos rendimentos em etanol em torno de 10\%, resultados próximos ao encontrado por Sánchez et al. (2002) (9,4\%), enquanto que com a adição de furfural e ácido acético não se chegou a 4\%. Todavia, a produtividade em etanol foi significativamente inferior, mostrando eficiências de conversão da xilose em etanol abaixo de $23 \%$.

Os valores da determinação da velocidade específica máxima de crescimento $\left(\mu_{\max }\right)$ foram obtidos pelo ajuste linear dos valores experimentais de $\ln \left(\mathrm{X} / \mathrm{X}_{0}\right)$ em função do tempo. Esta determinação permitiu comprovar a inibição do processo pela adição ácido acético e de furfural, além de verificar no experimento controle e com adição de HMF taxas de crescimento de 0,03 e $0,02 \mathrm{~h}^{-1}$, respectivamente.

Os resultados mostram que a levedura Pachysolen tannophilus é inibida pela presença de ácido acético e furfural, indicando que o microrganismo pode não ser eficiente em amostras de prétratamento da biomassa lignocelulósica, em especial oriundas de pré-tratamento químico, que contêm uma mistura destes inibidores.

\section{CONCLUSÕES}

A levedura Pachysolen tannophilus se mostrou capaz de crescer na presença isolada hidrozimetilfurfural, mas apresentou inibição quase que completa na presença de ácido acético e de furfural. A presença apenas de hidroximetilfurfural, na concentração de $0,40 \mathrm{~g} / \mathrm{L}$, mostrou efeito positivo na fermentação etanólica, gerando maior eficiência do processo fermentativo (22,9\%). A influência dos principais inibidores obtidos do pré-tratamento químico da biomassa lignocelulósica indicam que esta levedura pode não ser o microrganismo adequado para a produção de etanol de segunda geração. 


\section{AGRADECIMENTOS}

À Embrapa Agroenergia, pelo auxílio à pesquisa e doação da levedura.

\section{REFERÊNCIAS}

ALMEIDA, J. R. M.; FÁVARO, L. C. L. Leveduras para produção de etanol de sorgo sacarino. Agroenergia em Revista, ed. 3, ago. 2011.

BALLESTEROS, M. Estado del desarrollo tecnológico del aprovechamiento de biomasa: biocombustibles para el sector del transporte. Energía, v.161, p. 29-34, 2001.

CABRAL, J.C.A.; SILVA, J.P.A.; ROBERTO, I.C. Influência do pH na produção de etanol por Pichia stipitis. In: Encontro Latino Americano de Pós-Graduação, 9 , 2005, Lorena-SP.

DEMIRBAS, A. Bioethanol from cellulosic materials: a renewable motor fuel from biomass. Energy Sources, v. 27, p. 327-337, 2005.

FUGITA, T. Desempenho de leveduras que metabolizam xilose para produção de etanol em hidrolisado hemicelulósico de bagaço de cana. 2010. Dissertação (Mestrado em Microbiologia) Universidade Estadual Paulista.

GARCÍA-CUBERO, M. T.; BELLIDO, C.; BOLADO, S.; COCA, M.; LUCAS, S.; GONZÁLEZBENITO, G. Effect of inhibitors formed during wheat straw pretreatment on ethanol fermentation by Pichia stipitis. Bioresource Technology, v. 102, p. 10868-10874, 2011.

GÍRIO, F. M.; FONSECA, C; CARVALHEIRO, F.; DUARTE, L. C.; MARQUES, S. BOGELLUKASIK, R. Hemicelluloses for fuel ethanol: a review. Bioresource Technology, Oxon, v. 101, n. 13, p. 4775-4800, 2010.

HAYES, D. J. An examination of biorefining processes, catalysts and challenges. Catalysis Today, v; 145, p. 138-151, 2009.

MACHADO, C. M. M. Microrganismos na produção de biocombustíveis líquidos. Editora Técnica. Brasília - DF. Embrapa, 2013. 319 p.

MILLER, G. L., Use of dinitrosalicylic acid reagent for determination of reducing sugar. Analytical Chemistry, v.31, n. 3, p. 426-428, 1959.

MORAES, D. C.; MURARI, C. S.; AQUINO, P. L. M.; BUENO, G. F.; DEL BIANCHI, V. L. Avaliação da fermentação aeróbia para produção de etanol a partir da xilose por linhagens de leveduras isoladas da casca de uva (Vitis spp). Revista Brasileira de Produtos Agroindustriais, v. 15, n. 2, p. 117-122, 2013.

MORAES, D. C.; PEREZ, C. A.; DORTA, C. Seleção de microrganismos fermentadores de xilose. Revista Analytica, ano 8, n. 47, p. 59-67, jun/jul 2010.

PEREIRA Jr., N. Biomassas residuais de composição lignocelulósica para a produção de etanol e o contexto de refinaria, 2007.

ROSSELL, C.E.V. Evolução tecnológica da produção de etanol. Expectativas futuras: destilarias 
otimizadas, etanol da hidrólise de bagaço. In: Reunião Anual da SBPC, 60ª 2008, Campinas-SP.

SÁNCHEZ, S.; BRAVO, V.; CASTRO, E.; MOYA, A. J.; CAMACHO, F. The fermentation of mixtures of D-glucose and D-xylose by Candida shehatae, Pichia stipitis and Pachysolen tannophilus to produce ethanol. Journal of Chemical Technology and Biotechnology, v. 77, p. 641-648, 2002.

SILVA, J. P. A.; MUSSATTO, S. I.; ROBERTO, I. C.; TEIXEIRA, J. A. Ethanol production from xylose by Pichia stipitis NRRL Y-7124 in a stirred tank bioreactor. Brazilian Journal of Chemical Engineering, v. 28, n. 1, p. 151-156, jan-mar 2011.

ZHAO, L.; ZHANG, X.; TAN, T. Influence of various glucose/xylose mixtures on ethanol production by Pachysolen tannophilus. Biomass and Bioenergy, v. 32, n. 12, p. 1156-1161, 2008 